\title{
Editorial
}

\section{Functional Dyes}

\author{
Ahmed El-Shafei, ${ }^{1}$ Ashraful Islam, ${ }^{2}$ and Md. Akhtaruzzaman ${ }^{3}$ \\ ${ }^{1}$ Polymer and Color Chemistry Program, North Carolina State University, Raleigh, NC 27695, USA \\ ${ }^{2}$ Photovoltaic Materials Unit, National Institute for Materials Science (NIMS), 1-2-1 Sengen, Tsukuba, \\ Ibaraki Prefecture 305-0047, Japan \\ ${ }^{3}$ Solar Energy Research Institute, Universiti Kebangsaan Malaysia (UKM), 43600 Bangi, Selangor, Malaysia \\ Correspondence should be addressed to Ahmed El-Shafei; ahmed_el-shafei@ncsu.edu
}

Received 20 November 2013; Accepted 20 November 2013

Copyright (C) 2013 Ahmed El-Shafei et al. This is an open access article distributed under the Creative Commons Attribution License, which permits unrestricted use, distribution, and reproduction in any medium, provided the original work is properly cited.

Functional dyes have received considerable interest in the last ten years in the academia and industry due to their wide hightech applications. This special issue features a collection of high-quality scholarly work addressing the latest innovations in nanostructuring of materials with emphasis on solar cells, sustainability, and medicinal dyes.

We sincerely hope that this collection will become an international forum for researchers to provide the most recent advances, developments, and ideas in the field of functional dyes.

On the topic of dye-sensitized solar cells (DSSCs), a few articles are featured in this issue that discuss new findings in DSSCs.

M. R. Karim et al. studied multiwalled carbon nanotube (MWNT) coated with conducting polyaniline (PAni) nanocomposites for quasi-solid-state electrolyte layer in the dyesensitized solar cells (DSSCs). The use of MWNT-PAni nanoparticles was shown to enhance the total conversion efficiency. An ionic liquid of 1-methyl-3-propyl imidazolium iodide (PMII) and the hybrid MWNT-PAni nanocomposites were placed between the dye-sensitized porous $\mathrm{TiO}_{2}$ and the Pt counter electrode without adding iodine and they achieved a moderately higher cell efficiency (3.15\%) than that containing bare PMII (0.26\%).

M. D. Akhtaruzzaman et al. successfully applied an indoline dye (D-1) as a cosensitizer for improving the spectral response of black dye in dye-sensitized solar cells (DSCs). It was shown that D-1 effectively increases the short-circuit photocurrent density by offsetting the competitive light absorption by $\mathrm{I}^{-} / \mathrm{I}_{3}{ }^{-}$electrolyte in the wavelength region
350-500 nm when adsorbed on the $\mathrm{TiO}_{2}$ nanocrystalline films in a mixed dye system. The DSCs containing the D-1 and black dye achieved a power conversion efficiency of $9.80 \%$ with higher short-circuit photocurrent of $19.54 \mathrm{~mA} / \mathrm{cm}^{2}$ compared to the system of black dye without cosensitization under standard AM 1.5 sunlight.

S. P. Singh et al. developed novel Ru (II) complex coded as SPS-02. This complex showed appreciably broad absorption range. SPS-02 was used as a photosensitizer in nanocrystalline $\mathrm{TiO}_{2}$ dye-sensitized solar cell application and achieved efficient sensitization of nanocrystalline $\mathrm{TiO}_{2}$ over the whole visible range, extending into the near IR region (ca. $1000 \mathrm{~nm}$ ) with short-circuit photocurrent density $\left(J_{\mathrm{sc}}=9.13 \mathrm{mAcm}^{-2}\right)$ and conversion efficiency $(\eta=2.09 \%)$ compared with complex cis $[\mathrm{Ru}(\mathrm{H} 2 \mathrm{dcbiq}) 2(\mathrm{NCS}) 2]$ (1) under an irradiation of full sunlight $\left(100 \mathrm{~mW} \mathrm{~cm}^{-2}\right)$.

On the topic of dyes for medical applications, novel dyes based on different chromophores were developed and their biological activities for their antioxidant and cytotoxic activities were evaluated.

K. M. Elattar et al. developed novel nine substituted azo dyes derivatives $\mathbf{2 - 1 0}$ based on antipyrine. The effects of the nature and orientation of the substituents on the biological activity were evaluated. The newly synthesized compounds were screened for their antioxidant and cytotoxic activity. The data showed clearly that most of the compounds exhibited good antioxidant and cytotoxic activities.

A. A. Fadda et al. developed a series of porphyrin derivatives (2a-f) in high yields using a new method via a capping mechanism. These dyes were used as a model to study the free 
radical-induced damage of biological membranes and the protective effects of these porphyrins. It was demonstrated that these dyes were effective in the inhibition of the free radical-induced oxidative haemolysis of rat blood cells. Dyes 2d and $2 \mathbf{f}$ which bear methoxy functionality exhibited markedly higher antihaemolysis activity than that of the other analogs.

Finally, on the topic of color removal from textile effluents using eco-friendly and inexpensive materials, one article highlighted the use of date palm fibers in removing crystal violet.

M. Alshabanat et al. studied the adsorption of crystal violet $(\mathrm{CV})$ onto date palm fibers (DPF) in aqueous solution at $25^{\circ} \mathrm{C}$. The experimental maximum adsorption capacity value was $0.66 \times 10^{-6}$. Langmuir, Freundlich, Elovich, and Temkin models were applied to describe the equilibrium isotherms. The influence of $\mathrm{pH}$ and temperature on dye removal was evaluated. The percentage removal of $\mathrm{CV}$ dye by adsorption onto DPF at different $\mathrm{pH}$ and temperatures showed that these factors play a role in the adsorption process.

By compiling these papers, we sincerely hope to enrich our readers and researchers who are interested in functional dyes with the most recent progress in the field of functional dyes for solar energy, medical and ecofriendly wastewater applications.

The guest editors are grateful to all authors that contributed to this issue with high-quality scholarly research.

Ahmed El-Shafei

Ashraful Islam

Md. Akhtaruzzaman 

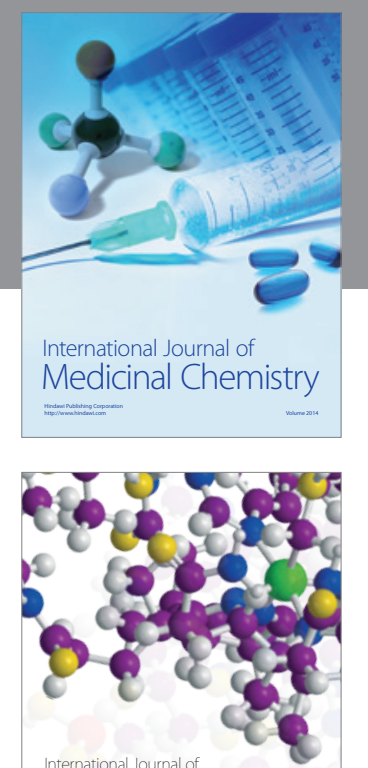

\section{Carbohydrate} Chemistry

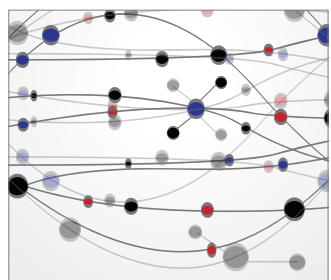

The Scientific World Journal
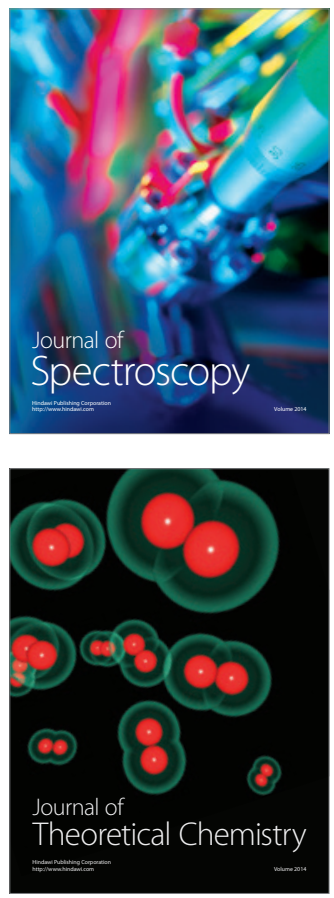
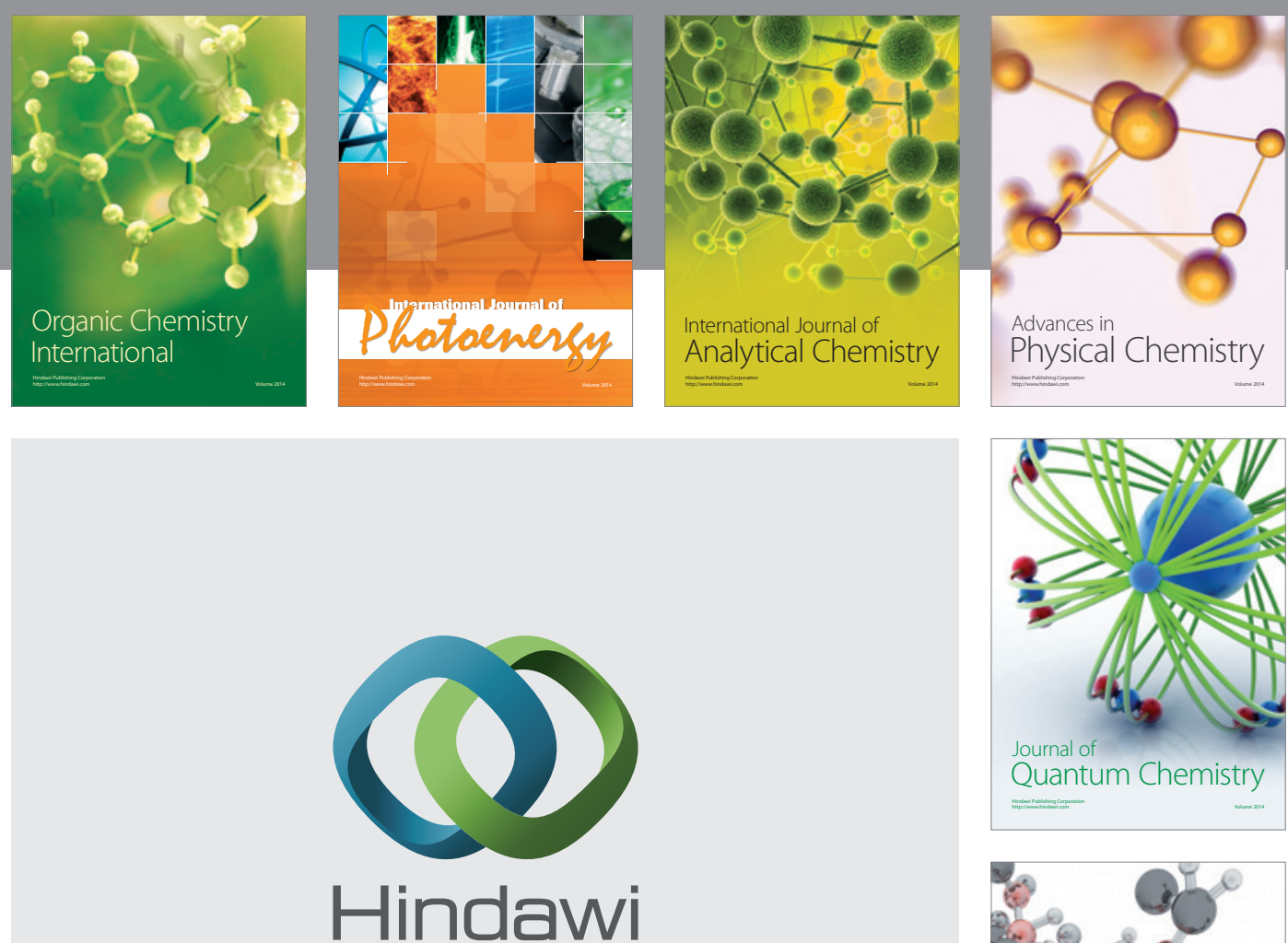

Submit your manuscripts at

http://www.hindawi.com

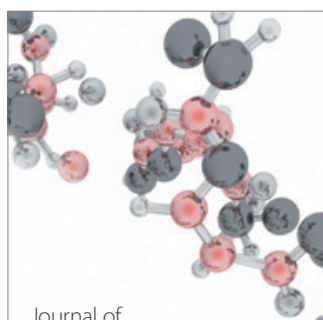

Analytical Methods

in Chemistry

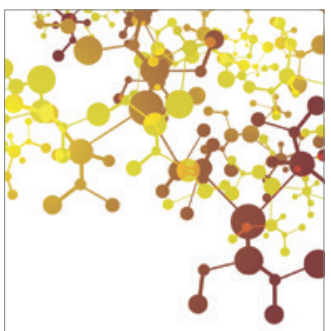

Journal of

Applied Chemistry

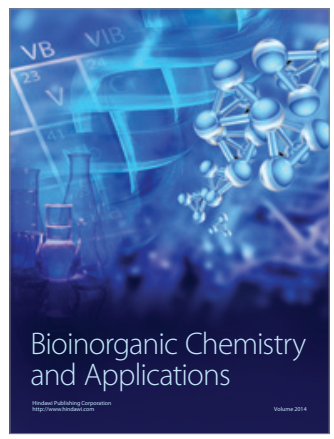

Inorganic Chemistry
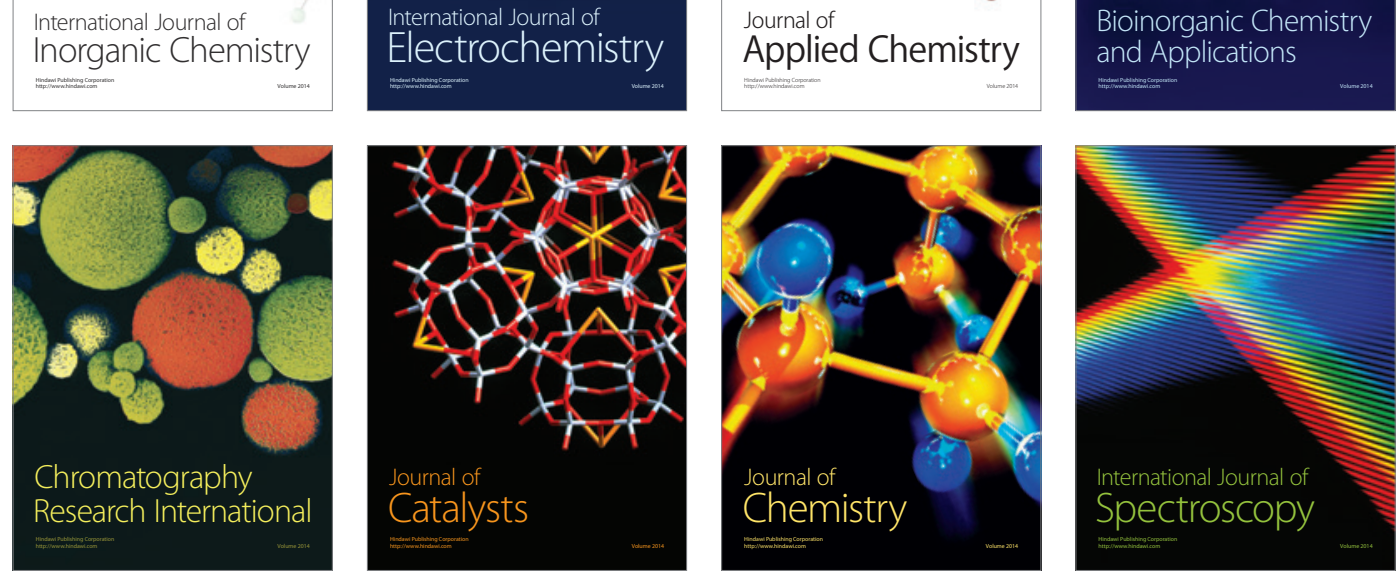